\title{
A Rare Case of Asymptomatic Emphysematous Pyelonephritis
}

\author{
Yeung AM H*, Cheng CH, Chu PSK, Man CW and Chau H \\ Department of Surgery, Tuen Mun Hospital, Hong Kong \\ *Corresponding author: Yeung AMH, Department of Surgery, Tuen Mun Hospital, Hong Kong
}

\begin{tabular}{ll}
\hline ARTICLE INFO & ABSTRACT \\
$\begin{array}{l}\text { Received: } \\
\text { Published: August 05, } 2019\end{array} \quad \begin{array}{l}\text { Asymptomatic emphysematous pyelonephritis is a rare but potentially life-threatening } \\
\text { disease. Diabetes mellitus is the most recognised risk factor. Aim of this case report is to } \\
\text { review evidence of emphysematous pyelonephritis to identify risk factors and treatment } \\
\text { options. }\end{array}$
\end{tabular}

Citation: Yeung AM $\mathrm{H}$, Cheng $\mathrm{CH}$, Chu PSK, Man CW, Chau H. A Rare Case of Asymptomatic Emphysematous Pyelonephritis. Biomed J Sci \& Tech Res 20(3)-2019. BJSTR. MS.ID.003456.

\section{Introduction}

Emphysematous urinary tract infection is a rare spectrum of disease which can potentially run a fulminant course ending in severe morbidity or even mortality. It can manifest as cystitis, pyelitis or pyelonephritis which need to be distinguished carefully as they carry different implication in treatment options and prognosis. Usual presentation of emphysematous pyelonephritis is similar to those of pyelonephritis, including fever, chills, loin pain. In our case, this rare condition was incidentally diagnosed during a regular plain radiograph for follow up of the patient's stone disease, which was subsequently confirmed with non-contrast Computed Tomography (CT).

\section{Case Report}

A 53 years old gentleman had known history of diabetes mellitus for 7 years. Diabetic control was poor all along because of poor drug compliance and high defaulted rate of medical followup. The disease progressed aggressively and was complicated with retinopathy and nephropathy. He presented to medical officer with deteriorating renal function. Ultrasound of urinary system showed right hydronephrosis and left renal stone. Plain radiograph of Kidney-Ureter-Bladder (KUB) showed a right distal ureteric stone. Plain CT subsequently confirmed $2 \mathrm{~cm}$ obstructing right distal ureteric stone and tortuous ureter with a $0.9 \mathrm{~cm}$ left renal stone. Ureteroscopic lithotripsy was performed which revealed a $2.8 \mathrm{~cm}$ tightly impacted stone. Adjuvant extracorpeal shockwave lithotripsy failed to tackle residual ureteric stones. Therefore, another ureteroscopic lithotripsy was performed for complete stone clearance.

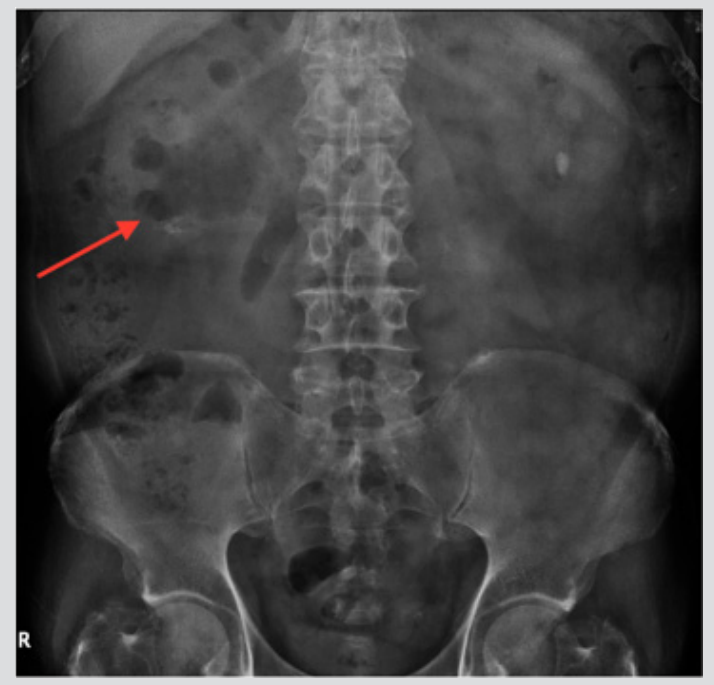

Figure 1: Plain radiograph showing gas in bilateral collecting system and left renal stone. 
However, the right kidney was still hydronephrotic. Renal functional scan (MAG-3) 12 months post-operative confirmed obstructed right kidney likely at right upper ureter. Right kidney differential function was at $26.9 \%$. Plain CT prior to reconstruction surgery showed gaseous collection in bilateral collection system down to urinary bladder, which was more severe on the right side, and bilateral non-obstructing renal stones but no ureteric stones (Figures 1-3).

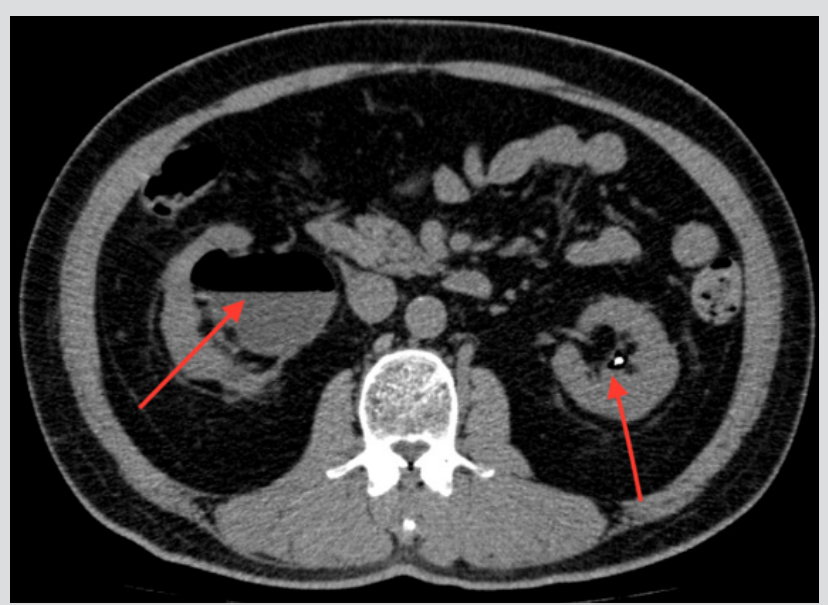

Figure 2: Plain computed tomography showing gas in bilateral collecting system.

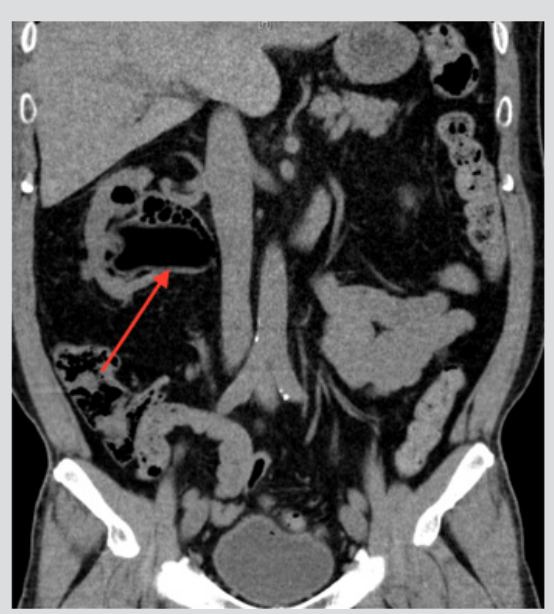

Figure 3: Plain computed tomography showing gas in bilateral collecting system.

Patient was, however, asymptomatic. There were no clinical features suggestive of urosepsis. Physical examination was unremarkable. Since the last endourological procedure Right URSL was performed 18months ago, the possibility of gas collection post-instrumentation is minimal. The clinical diagnosis was asymptomatic emphysematous pyelonephritis. He was then admitted to our urology unit for further management. Urine culture showed Escherichia coli. According to bacteriology, 2-weeks Intravenous Ceftriaxone was commenced. No urinary drainage was performed in view of stable vital signs and asymptomatic condition. Insulin regimen was modified, and his diabetes improved. His antibiotics regimen was stepped down to oral levofloxacin for 2 more weeks. He was discharged after 4 weeks of antibiotics.

K-U-B X-ray 3 months after diagnosis of emphysematous pyelonephritis showed complete resolution of previously seen gaseous collection. The patient remained asymptomatic all along.

\section{Discussion}

For emphysematous pyelonephritis, the causative agent of infection is mainly Escherichia coli and Klebsiella pneumonia up to $69 \%$ and $29 \%$ respectively [1]. The main investigative tool is computed tomography. Three classifications, i.e. Huang JJ et al., Wan YL et al. and Michaeli et al. have been described to determine treatment and prognosis, mainly depending on the radiological findings and also associated risk factors. Multiple studies have recognized uncontrolled diabetes mellitus to be the most common associated factor up to $96 \%$ [2-5], while some reports show female predominance. $[1,5]$ The mainstay of treatment depends on clinical scenario and aforementioned classification. It includes intravenous antibiotics, and usually requires double J catheter insertion, percutaneous drainage or even nephrectomy. Despite prompt treatment, mortality rate can still be up to $25 \%$. [2] In our reported case, since the patient is completely asymptomatic, we decided to put him on intravenous antibiotics alone and close monitoring of vital signs. Moreover, to avoid flaring up of sepsis in a stable patient, neither ureteric stenting nor percutaneous drainage was performed.

Several case reports from Europe, Korea, and India in recent few years also described similar circumstances. All of them chose conservative management, either by antibiotics alone, or with double J stent insertion. All cases remain disease free in follow-up. The nature of asymptomatic pyelonephritis is yet to be elucidated given its rarity. It could be an early sign for a full blown sepsis or embedded in latency with medical therapy. Prompt treatment of both the infection and underlying risk factors is still advocated to prevent fatal disease progression.

\section{Conclusion}

Emphysematous pyelonephritis is known to be an uncommon but life-threatening condition. It is even rare for these patients to be asymptomatic. Conservative treatment for asymptomatic emphysematous pyelonephritis has shown favourable outcome in a few case reports. However, more aggressive approach should be considered if patients deteriorate in view of the fulminant course of disease. Mortality rate is reported up to $13.5 \%$ [5] for emphysematous pyelonephritis. However, it has been much reduced with the advancement of antibiotics combined with minimally invasive techniques. More studies will be required to further validate the underlying pathogenesis. Future studies should also focus on reviewing cases in current database to identify patient selection criteria for different treatment modalities and facilitate development of management guidelines. 


\section{References}

1. Huang JJ, Tseng CC (2000) Emphysematous pyelonephritis: Clinicoradiological classification, management, prognosis, and pathogenesis. Arch Intern Med 160(6): 797-805.

2. Wan YL, Lee TY, Bullard MJ, Tsai CC (1996) Acute gas-producing bacterial renal infection: Correlation between imaging findings and clinical outcome. Radiology 198(2): 433-438.

3. Falagas ME, Alexiou VG, Giannopoulou KP, Siempos II (2007) Risk factors for mortality in patients with emphysematous pyelonephritis: A metaanalysis. J Urol 178: 880-885.

ISSN: 2574-1241

DOI: 10.26717/BJSTR.2019.20.003456

Yeung AM H. Biomed J Sci \& Tech Res

cC) This work is licensed under Creative Commons Attribution 4.0 License

Submission Link: https://biomedres.us/submit-manuscript.php
4. Snokeir AA, El-Azab M, Mohsen T, El-Diasty T (1997) Emphysematous pyelonephritis: A 15-year experience with 20 cases. Urology 49: 343346 .

5. Somani BK, Nabi G, Thorpe P, Hussey J, Cook J, et al. (2008) Is percutaneous drainage the new gold standard in the management of emphysematous pyelonephritis? Evidence from a systematic review. J Urol 179: 1844-1849.

$\begin{array}{ll}\text { BIOMEDICAL } & \text { Assets of Publishing with us } \\ \text { RESEARCHES } & \text { - Global archiving of articles } \\ & \text { - Immediate, unrestricted online access } \\ & \text { - Rigorous Peer Review Process } \\ \end{array}$

